\title{
COVID-19 Perceptional Disparity Among Dental Healthcare Personnel at King Faisal University: Applying Health Belief Model
}

\author{
Elwalid Fadul Nasir ${ }^{1} \quad$ Ahmed Khalid Elhag ${ }^{2}$ Hatim Mohammed Almahdi ${ }^{3}$
}

${ }^{1}$ Department of Preventive Dentistry, College of Dentistry,

King Faisal University, Al Ahsa, Saudi Arabia

2Department of Restorative Dentistry, College of Dentistry, King Faisal University, Al Ahsa, Saudi Arabia

${ }^{3}$ Department Oral and Maxillofacial Surgery, College of Dentistry, King Faisal University, Al Ahsa, Saudi Arabia

\begin{abstract}
Address for correspondence Hatim Mohammed Almahdi, BDS, MFD RCSI, MSc, PhD, Department Oral and Maxillofacial Surgery, College of Dentistry, King Faisal University, P.O. 380, Al Ahsa, 31982, Saudi Arabia (e-mail: hyagoob@kfu.edu.sa).
\end{abstract}

Eur J Dent:2020;14(suppl S1):S56-S62

\section{Abstract \\ Keywords \\ - COVID-19 \\ - health belief model \\ - perception \\ - self-efficacy \\ - severity}

Objectives In Saudi Arabia, more than 100, 000 cases of COVID-19 have been reported, and more than 4,000 in Al Hofuf to date. Dental healthcare personnel are at a higher risk of COVID-19 due to their exposure to saliva, blood, and aerosol/droplet during their daily practice. Their perceptions of COVID-19 drive their behaviors.

Materials and Methods A cross-sectional online survey to assess COVID-19 related perceptions and possible disparities between them.

Statistical analysis Data were analyzed using the Statistical Package for the Social Science, version 23 (IBM SPSS). Descriptive analyses were performed using frequencies and percentages for categorical variables, mean and $( \pm$ SD) for numerical variables. Bivariate analyses were assessed using $t$-test and one-way ANOVA, with a 95\% confidence interval $(\mathrm{Cl})$.

Results With a response of $75 \%$ (150), results showed that there were perceptional disparities: students and technical staff perceived more barriers to preventive measures compared to faculties with a mean difference of $(-0.145 \mathrm{SD} \pm 0.580$, $p=0.802, \mathrm{Cl}-1.29 / 1.00$ and $-2.433, \mathrm{SD} \pm 0.94, p=0.010)$, respectively. This was also shown in threat perception with a mean difference of $(2.525, \mathrm{SE} \pm 0.917, \mathrm{Cl} 0.71 / 4.34$, $p=0.0 .007)$. Students perceived more threat than clerks did with a mean difference of $(1.281, \mathrm{SE} \pm 0.569, \mathrm{Cl}-0.16 / 2.41, p=0.026)$, while clerks perceived less threat than the technical staff with a mean difference of $(-2.790, \mathrm{SE} \pm 0.860, \mathrm{Cl}-4.49 /-1.09$, $p=0.001$ ).

Conclusions There was a clear disparity in the perceptions among the different categories of participants. More emphasis on the training and preparedness of the dental healthcare personnel is required.
DoI https://doi.org/ $10.1055 / \mathrm{s}-0040-1716782$ ISSN 1305-7456. (c) 2020. European Journal of Dentistry.

This is an open access article published by Thieme under the terms of the Creative Commons Attribution-NonDerivative-NonCommercial-License, permitting copying and reproduction so long as the original work is given appropriate credit. Contents may not be used for commercial purposes, or adapted, remixed, transformed or built upon. (https://creativecommons.org/licenses/by-nc-nd/4.0/) Thieme Medical and Scientific Publishers Pvt. Ltd., A-12, 2nd Floor, Sector 2, Noida-201301 UP, India 


\section{Introduction}

The World Health Organization (WHO) declared the Coronavirus disease 2019 (COVID-19) as a pandemic with significant mortality and morbidity. ${ }^{1}$ An epidemic means the virus should be new, have wide geographic distribution, and spread via human-to-human transmission in an explosive outbreak. ${ }^{2}$

Symptoms caused by SARS-CoV-2 transmission begin with an immense viral load within the respiratory tract secretions and manifests as typical pneumonia or acute respiratory distress syndrome (ARDS), including fever, dry cough, and myalgia. Furthermore, nausea, diarrhea, reduced sense of smell, and abnormal taste sensation could also present. ${ }^{3,4}$

Virus transmission is by air, direct contact from person to person, through surfaces that had been contaminated, and respiratory droplets and aerosols produced when an infected person coughs or sneezes. ${ }^{5}$ The faecal-oral route might also be a mode of transmission. ${ }^{6}$

Aerosols are particles formed by solid or liquid particles dispersed and suspended in the air; they may contain microorganisms and other components. The particles in a bioaerosol are generally small in diameter; however, larger sizes $(1.0-5.0 \mu \mathrm{m})$ remain typically in the air, whereas larger particles are deposited on the surfaces remain for hours. ${ }^{7.8}$

Droplets of saliva are discharged by sneezing or coughing, and their particle size is generally 1 to $5 \mathrm{~mm}$. They spread in the space for approximately 1 to $2 \mathrm{~m}$ from the source of infection. ${ }^{8}$ The possibility of 2019-nCoV to infect the salivary glands was demonstrated by Chin et al. ${ }^{9}$

Dental healthcare personnel (DHCP) (dentists, dental students, dental assistants, dental technicians, administrators and receptionists) are at high-risk of infection due to their exposure to saliva, blood, and aerosol/droplet production during the majority of dental procedures. ${ }^{10,11}$ Aerosols mix with the saliva of the patient, which become airborne; thus, the risk of transmitting the COVID-19 to the dentists and patients becomes exceptionally high. ${ }^{10,11}$

Healthcare workers are deeply affected by the COVID-19 pandemic. For example, in Italy, more than 13,000 healthcare workers were affected by the death of 165 medical doctors, including dentists. ${ }^{11,12}$ DHCP need to update their knowledge and skills regarding infection control and follow the protocols recommended by the relevant authorities to protect themselves and their patients against infections.

Due to the lack of standard guidelines for the preparedness of dental clinics and personnel, dental care provision has significantly decreased or completely stopped in several affected countries, including Saudi Arabia. This also increased the burden on hospitals' emergency departments, which was already struggling with the pandemic. This lack of guidelines can also increase nosocomial infections. ${ }^{13}$

In Saudi Arabia, more than 100, 000 cases of COVID-19 have been reported, and more than 4,000 in Al Hufuf to date. ${ }^{14}$ The dental practices have been instructed by the authorities to carry out only emergency treatment of patients that obviate aerosol production. ${ }^{15}$

Health psychological models commonly employed to explain, predict and facilitate health behaviors contain a wide variety of components. There is evidence that the efficacy and effectiveness of interventions to promote health behavior change, depending on the use of behavioral models. . $^{16,17}$

The health belief model (HBM) is considered among psychosocial models of health-related behavior as the most frequently used and significantly related to health behaviors. It is principally developed to explain an individual's health actions under conditions of uncertainty. ${ }^{16} \mathrm{HBM}$ has most commonly been employed in the context of health service issues and compliance with medical treatment. ${ }^{16}$ It has been a positive tool, and can almost certainly be used to imply a more significant future effect on health behavior change. ${ }^{17}$

To combat an outbreak, DHCP should be aware of recent developments, especially those related to public health, and make efforts to prevent the transmission of such diseases. Some studies indicate the importance of improving healthcare workers' COVID-19 knowledge training programs on infection control. ${ }^{18}$

Hence, the present study among DHCP in King Faisal University (KFU) dental polyclinic was undertaken to assess the level of COVID-19 related perceptions and possible disparities between the DHCP categories.

\section{Materials and Methods}

A cross-sectional online survey was conducted between March 3 to April 14, 2020, among DHCP at the College of Dentistry KFU. All DHCP members were invited to participate via their WhatsApp groups. On accessing the link (https://forms.gle/D3VhQgQVEirFH3gF6), there are standardized instructions about the aim of the study, and procedures to complete the survey. By submitting the form, the participant is considered to be providing consent to the study. The survey was secured as not to be taken twice from the same electronic device. Anonymity and confidentiality were assured by way of no gathering of personal information. The questionnaire was available in both languages, Arabic and English. This study obtained approval from the Research Ethics Committee at the College of Dentistry KFU.

\section{Data Collection}

The survey instrument was based on HBM constructs of self-efficacy, perceived threat to COVID-19, as well as total benefits from and barriers to the preventive measures. ${ }^{19}$ Besides sociodemographic characteristics, health-related information and COVID-19 related history were collected. Respondents completed subscales assessing the HBM constructs. All items were rated on five-point Likert's scales (from strongly disagree to strongly agree) and were summed to create HBM constructs

\section{Measures}

The threat to COVID-19 was measured by the sum of perceived susceptibility and perceived severity. A sum variable 
"perceived threat to COVID-19" (Cronbach's $\alpha$ 70.6\%) was constructed from the two items and was dichotomized on the mean score (12.91, S.E. \pm 0.235 ). Four items measured total benefits of the following preventive measures: "hand hygiene will always prevent me from getting COVID-19"; "I feel safer through hand hygiene"; "the social distancing prevents me from getting COVID-19"; "I feel safer by social distancing." A sum variable "total benefits of preventive measures COVID-19" (Cronbach's $\alpha$ 57.5\%) was constructed from the four items and dichotomized on the mean score (17.77, S.E. \pm 0.157$)$.

Four items measured total barriers to the following preventive measures: "my hands hurt when I do hand hygiene"; "I always forget hand hygiene"; "I feel bad with social distancing"; "I always forget social distancing." A sum variable "total barriers to preventive measures COVID-19" (Cronbach's $\alpha 49.3 \%$ ) was constructed from the two items and dichotomized on the mean score $(15.33$, S.E. \pm 0.235$)$.

Five items measured self-efficacy to prevent COVID-19: "maintaining good health is an important part of my life"; "I think I am a person who cares well for his general health"; "I think it is important for me to have good general health"; "I think it is important for me to avoid infectious diseases"; "IthinkIamapersonwhotakescorrecthealthmeasures." A sum variable "self-efficacy to prevent COVID-19" (Cronbach's $\alpha$ 64.1\%) was constructed from the two items and dichotomized on the mean score (22.59, S.E. \pm 0.13.7).

\section{Data Analysis}

We analyzed data using the Statistical Package for the Social Science, version 23 (IBM SPSS). We performed descriptive analyses using frequencies and percentages for categorical variables and mean and ( \pm SD) for numerical variables. Bivariate relationships between the dependent variables and independent variables were assessed using $t$-test and oneway ANOVA, with 95\% confidence interval (CI); a two-sided significance level of $\leq 5 \%$ was implied for all analyses.

\section{Results}

\section{Sample Profile}

A total of (150) individuals participated in the survey with a mean age of 28.35 years ( $S D \pm 9.8$ ), students 21.5 years ( $S D \pm$ 2.3 ), clerks 30.8 years ( $S D \pm 5.3$ ), technical staff 28.7 years ( $S D$ \pm 5.0 ) and faculties 46.3 years ( $S D \pm 7.0$ ). Males represented most of the participants, $61 \%$ (92); slightly less than half had university or higher education, 48.7\% (73). Students formed almost $50.7 \%$ (76) of the participants, followed by clerks $23 \%$ (35), faculties $16 \%$ (24), and technical staff $10 \%$ (15). Saudis formed the majority $84 \%$ (126), with almost all having no history of travelling during the past 14 days, $98.7 \%$ (148) (-Fig. 1).

Regarding reported health status, most of the participants perceived having good health status $84 \%$ (126), reported no medical consultation in the past month 88\% (132), no respiratory symptoms $84 \%$ (126), and no organic/mental illness 94\% (141). Almost all the participants reported no relation neither with COVID-19 infection nor with anyone with COVID-19 infection, 99.3\% (149) (-Fig. 2).

Most of the participants (60\%) perceived high selfefficacy. Technical staff scored the highest score (73.3\%), followed by faculties $(70.8 \%)$, clerks $(62.9 \%)$, and students scored the least (52.6\%). These results show the effect of the decreased score by the students on the total sample score. Most of the faculties scored the highest perceived threat of COVID-19 (66.7\%), followed by students (50\%), clerks (45.7\%), and then technical staff (33.3\%), while half $(50 \%)$ of the total sample perceived the threat. The weak score in relation to the perceived threat of all staff members compared with the faculties was evident. Most of all types of staff members scored high in the benefits of preventive measures against COVID-19, ranging from $62.9 \%$ to $70.8 \%$, with the faculties having the highest score. Less than half of the clerks (45.7\%) perceived barriers to preventive measures COVID-19, followed by faculties, with exactly half of them (50\%) perceiving barriers, more than half $(57.9 \%)$ of the students, and most (73.3\%) technical staff, scoring the

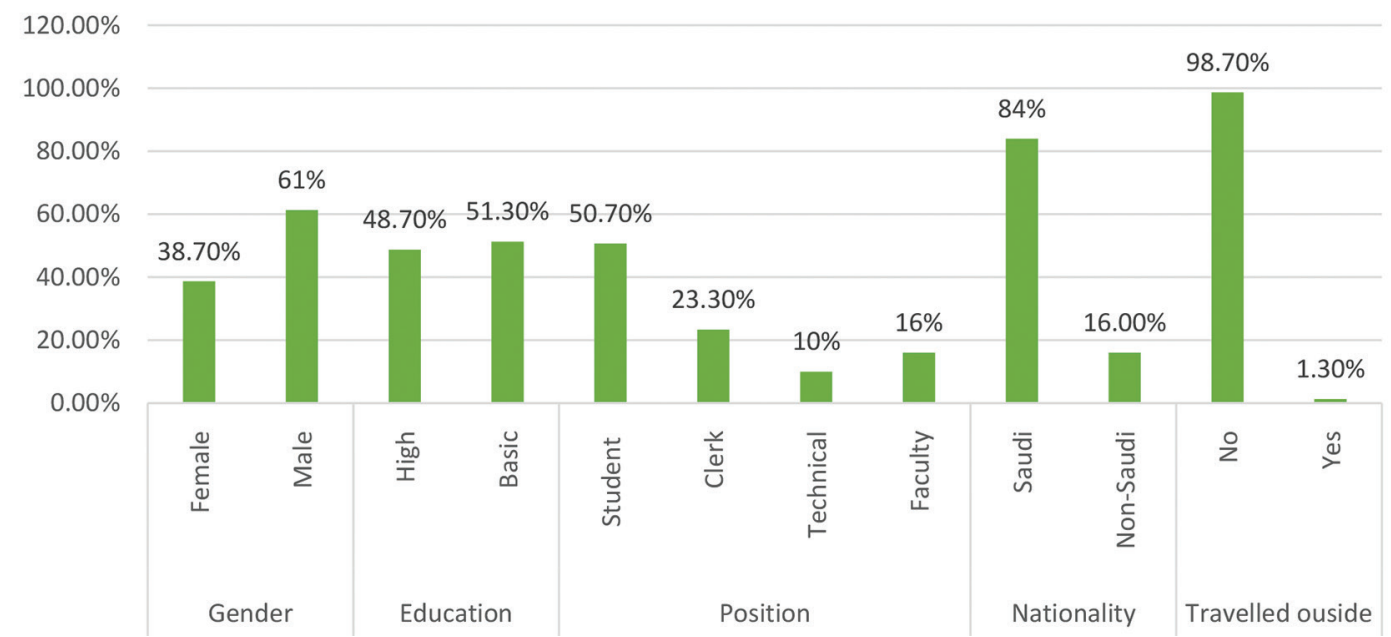

Fig. 1 Percentages distribution of the sociodemographic characteristics of the participants 


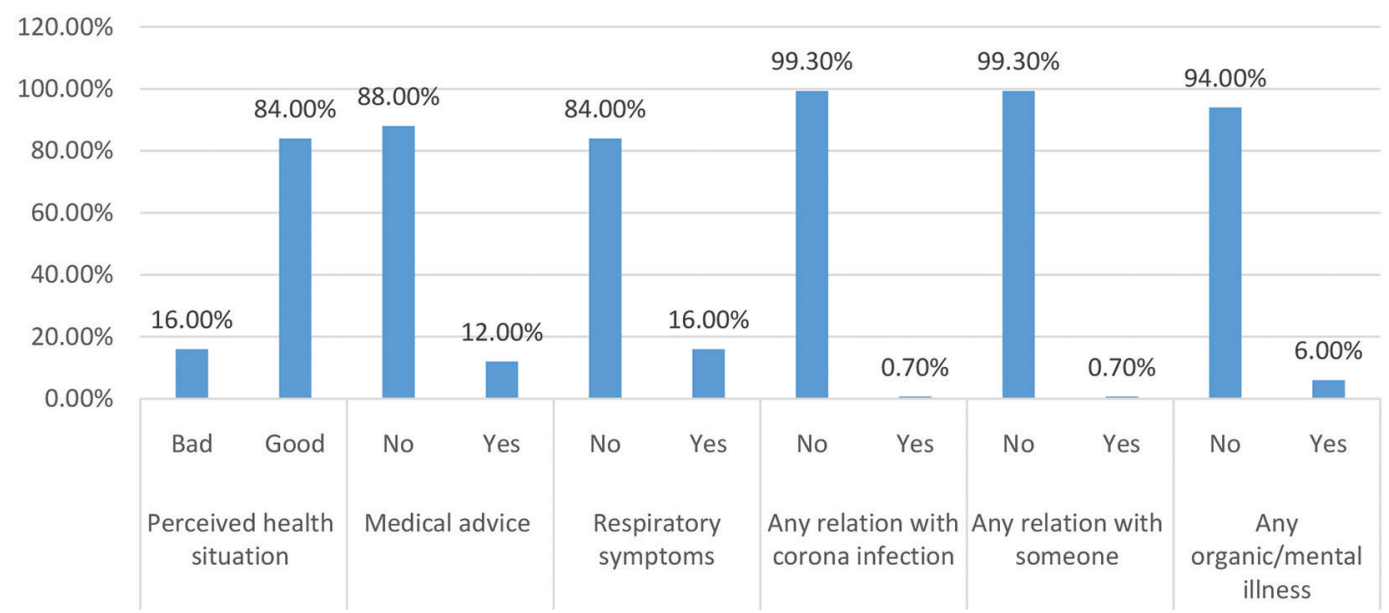

Fig. 2 Percentages distribution of reported health-related aspects

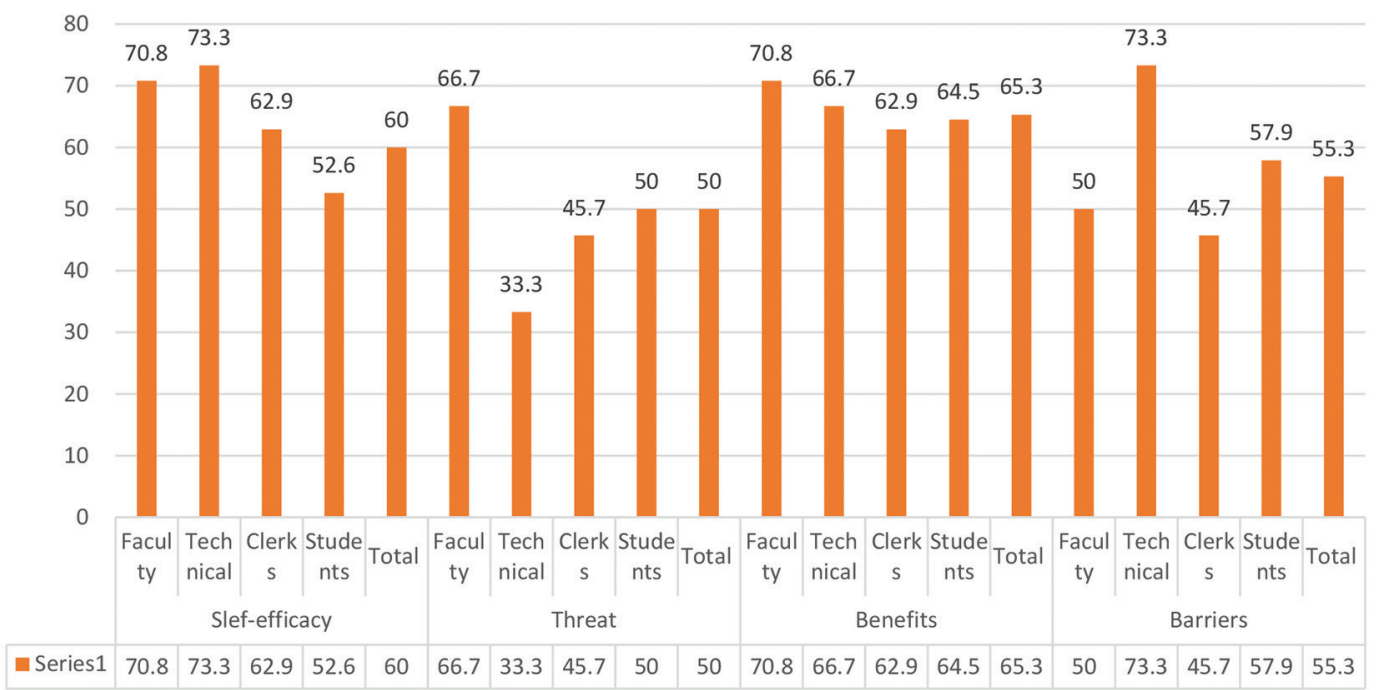

Fig. 3 Distribution of health belief model (HBM) constructs high score among position categories

highest percentages. The latter two groups strongly affected the total sample (55.3\%) score perceiving barriers ( - Fig. 3 ).

By conducting one-way ANOVA, the results showed that there were different mean scores in each category of position within the HBM constructs. There was no violation of the assumption of homogeneity of the variance, as there was no significance. In the sum of squares table, it is clear that there is a statistically significant difference in the threat constructs, while a difference in total barriers exists, even though not statistically significant.

Multiple comparisons (least significant difference [LSD]) showed that faculties statistically significantly perceived more barriers than technical staff, with a mean difference of $(-2.43$, S.E. $\pm 0.93, \mathrm{CI}-4.28 / 0.58, p=0.01)$. The table also shows students perceived more threat than clerks did, with a mean difference of (1.281, S.E. $\pm 0.57, \mathrm{CI}-0.16$ / 2.41, $p=0.026)$, as well as between technical staff and faculties, with a mean difference of $(2.53$, S.E. \pm 0.917 , CI 0.71 / 4.34, $p=0.0 .007)$. Also, clerks perceived threat more than the technical staff, with a mean difference of $(-2.790, \mathrm{SE} \pm 0.86$, CI -4.49 / - 1.09, $p=0.001)(-$ Table 1).

\section{Discussion}

Several epidemics (H1N1, H5N1, SARS, and MERS) have affected the world in the past and were successfully tackled with many types of research..$^{20}$ The COVID-19 pandemic has become one of the central health crises of the world recently. The pandemic has affected peoples' lives and the responses required such as quarantining of entire communities and social distancing, which abruptly changed daily life. Healthcare professionals, including DHCP who are in the frontlines and in contact with the infected patients, subject themselves to infection and deaths from COIVD-19..$^{21,22}$

Explanations for the preparedness of DHCP without contracting COVID-19 may include the study of the behavior of DHCP, which is determined by perceived self-efficacy, threat and perceived barriers and benefits using HBM. ${ }^{1723}$ Ideally, DHCP is expected to have a good understanding of the risk of COVID-19 at the workplace and about the preventive measures for reducing risk. However, this study found disparities among the categories of DHCP. Maintaining an adequate 
Table 1 HBM constructs' mean comparison among position categories (ANOVA)

\begin{tabular}{|c|c|c|c|c|c|c|}
\hline \multicolumn{3}{|l|}{ Categories } & Mean (SD) & S.E. & $95 \% \mathrm{Cl}$ & $\begin{array}{l}\text { Between- } \\
\text { component } \\
\text { variance }\end{array}$ \\
\hline \multirow[t]{7}{*}{ Self-efficacy } & \multicolumn{2}{|l|}{ Students } & $22.4(1.6)$ & 0.2 & $22.1 / 22.8$ & \\
\hline & \multicolumn{2}{|l|}{ Clerks } & $22.8(1.3)$ & 0.2 & $22.4 / 23.3$ & \\
\hline & \multicolumn{2}{|l|}{ Technical staff } & 22.7 (1.9) & 0.5 & $21.6 / 23.7$ & \\
\hline & \multicolumn{2}{|l|}{ Faculties } & $22.7(2.2)$ & 0.4 & 21.8/23.6 & \\
\hline & \multicolumn{2}{|l|}{ Total } & $22.6(1.7)$ & 0.1 & $22.3 / 22.7$ & \\
\hline & \multirow[t]{2}{*}{ Model } & Fixed effects & 1.7 & 0.1 & $22.3 / 22.7$ & \\
\hline & & Random effects & & $0.1^{\mathrm{a}}$ & $22.2^{\mathrm{a}} / 23.0^{\mathrm{a}}$ & -0.04 \\
\hline \multirow[t]{7}{*}{ Total benefits } & \multicolumn{2}{|l|}{ Students } & $17.8(1.6)$ & 0.2 & $17.4 / 18.1$ & \\
\hline & \multicolumn{2}{|l|}{ Clerks } & $17.9(1.8)$ & 0.3 & $17.31 / 18.5$ & \\
\hline & \multicolumn{2}{|l|}{ Technical staff } & $16.9(2.5)$ & 0.7 & $15.5 / 18.33$ & \\
\hline & \multicolumn{2}{|l|}{ Faculties } & $18.1(2.5)$ & 0.5 & $17.0 / 19.2$ & \\
\hline & \multicolumn{2}{|l|}{ Total } & $17.8(1.9)$ & 0.2 & $17.5 / 18.1$ & \\
\hline & \multirow[t]{2}{*}{ Model } & Fixed effects & 1.9 & 0.2 & $17.5 / 18.1$ & \\
\hline & & Random effects & & 0.2 & $17.2 / 18.4$ & 0.03 \\
\hline \multirow[t]{7}{*}{ Total barriers } & \multicolumn{2}{|l|}{ Students } & $15.2(2.9)$ & 0.3 & $14.5 / 15.9$ & \\
\hline & \multicolumn{2}{|l|}{ Clerks } & $15.3(2.3)$ & 0.4 & 14.6/16.1 & \\
\hline & \multicolumn{2}{|l|}{ Technical staff } & $14.1(2.6)$ & 0.7 & $12.6 / 15.5$ & \\
\hline & \multicolumn{2}{|l|}{ Faculties } & 16.53 .349 & 0.7 & $15.1 / 17.9$ & \\
\hline & \multicolumn{2}{|l|}{ Total } & $15.3(2.9)$ & 0.2 & $14.86 / 15.8$ & \\
\hline & \multirow[t]{2}{*}{ Model } & Fixed effects & $(2.8)$ & 0.2 & $14.9 / 15.8$ & \\
\hline & & Random effects & & 0.4 & $14.0 / 16.7$ & 0.35 \\
\hline \multirow[t]{7}{*}{ Threat } & \multicolumn{2}{|l|}{ Students } & $13.2(2.7)$ & 0.3 & $12.6 / 13.8$ & \\
\hline & \multicolumn{2}{|l|}{ Clerks } & $11.9(3.4)$ & 0.6 & $10.8 / 13.1$ & \\
\hline & \multicolumn{2}{|l|}{ Technical staff } & $14.7(2.4)$ & 0.6 & $13.4 / 16.1$ & \\
\hline & \multicolumn{2}{|l|}{ Faculties } & $12.2(2.2)$ & 0.5 & $11.3 / 13.2$ & \\
\hline & \multicolumn{2}{|l|}{ Total } & 12.9 (2.9) & 0.2 & $12.5 / 13.4$ & \\
\hline & \multirow[t]{2}{*}{ Model } & Fixed effects & $(2.8)$ & 0.2 & $12.5 / 13.4$ & \\
\hline & & Random effects & & 0.6 & $11.1 / 14.7$ & 0.80 \\
\hline
\end{tabular}

Abbreviations: HBM, health belief model; SD, standard deviation.

healthcare workforce in this crisis requires not only the adequate number of personnel but also maximizing the ability of each clinician to care for patients.

It is crucial to assess the perception of DHCP toward COVID19. Perceptions drive behavioral responses, both in general and concerning health behaviors such as complying with the preventive measures. Moreover, following a change in behavior, people tend to adjust their perception of risk downward. ${ }^{24}$

To the best of our knowledge, the present study is the first of its kind in Saudi Arabia to measure the perceived COVID-19 related preventive measures among DHCP using HBM. The overall response rate of 150 received out of 200 questionnaires forwarded online was $75 \%$ and is considered acceptable for online surveys. ${ }^{25}$

In this study, there was an apparent discrepancy between the DHCP in almost all HBM constructs. The lowest category scoring high self-efficacy was the students, followed by the clerks. This might not be adequate concerning their role as future dentists and promoters of oral health. A study found that self-efficacy was positively associated with academic and clinical performance among dental students. ${ }^{26,27}$ This also might direct attention to the training programs' contents to prepare students for their expected role. A study concluded that current undergraduate dental curricula do not adequately prepare dentists for the role of oral health promoters. ${ }^{28}$ Another study found that the introduction of an innovative oral health curriculum is a useful approach for teaching health profession students. ${ }^{29}$

The technical staff members, including the dentists, scored the lowest perceived threat of COVID-19. It was also evident that there was a significant disparity between the faculty members and the other categories regarding the threat. There might be a need to address, more clearly, the misconceptions and attitudes toward COVID-19.30

The disparity was evident in the perceived barriers, as a high percentage of technical staff and clerks perceived high 
barriers to preventive measures. Setting up good infection control practices in educational institutions is crucial in shaping future health professionals.

Barriers to preventive measures might lead to inadequate adherence with standard precaution measures. This is reflected in a study among dental school students in Iran, which found that there are complex and intertwined barriers of standard practice adherence. ${ }^{31}$ Another study found overall low understanding of precautions among medical students. ${ }^{32}$ Furthermore, a study in Egypt found that the performance of healthcare workers was poor for universal blood precautions. ${ }^{33}$ Recommendations of comprehensive education and empowering of DHCP toward oral health to ensure adequate care was recommended through the adoption of training programs with particular behavioral goals and right instructional strategies. ${ }^{34,35}$

\section{Conclusion}

This study has demonstrated that DHCP from KFU have a reasonable self-efficacy of COVID-19 and its transmission modes, while the faculty staff were significantly better than the others. As the world is currently experiencing a significant threat from the COVID-19 pandemic, which will reverberate well into the future, assessment of the perceptions of DHCP related to the disease is critical to identify knowledge gaps, and formulate and institute standardized, best practice guidelines against COVID-19 spread.

\section{Limitations and Strengths}

The major strength of this study is the use of HBM which is health behavior-focused, and there is evidence that the effectiveness of interventions to promote health behavior change and improve health outcomes could depend on the use of this model..$^{36}$ Another strength is that this study is based on HBM, enabling analysis and comparison with other studies using the model to explain health behavior.

The study has some limitations. First, a cross-sectional study provided a quick snapshot view, and hence causeeffect relationship cannot be ascertained. Second, the selfselection bias due to voluntary participation and information bias (social desirability) might have affected the results. Third, the possible confounding factors such as knowledge were not accounted and adjusted for in the analysis, which may have distorted the results. Therefore, the results of this study should be read, interpreted, and generalized cautiously. Finally, the theoretical constructs that constitute the HBM are broadly defined; furthermore, the HBM does not specify how constructs of the model interact with one another. Consequently, different operationalization of the theoretical constructs may not be strictly comparable

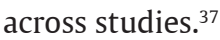

\section{Conflict of Interest}

None declared.

\section{References}

1 WHO. WHO announces COVID-19 outbreak a pandemic. Available at: http://www.euro.who.int/en/health-topics/ health-emergencies/coronavirus-covid-19/news/news/ 2020/3/who-announces-covid-19-outbreak-a-pandemic. Accessed May 22, 2020

2 Morens DM, Folkers GK, Fauci AS. What is a pandemic? J Infect Dis 2009;200(7):1018-1021

3 Zou L, Ruan F, Huang M, et al. SARS-CoV-2 viral load in upper respiratory specimens of infected patients. N Engl J Med 2020;382(12):1177-1179

4 Guan WJ, Ni ZY, Hu Y, et al. Clinical characteristics of 2019 novel coronavirus infection in China. medRxiv. Available at: https://www.medrxiv.org/content/10.1101/2020.02.06.20020 $974 \mathrm{v} 1$. Accessed 22 May 2020

5 van Doremalen N, Bushmaker T, Morris DH, et al. Aerosol and surface stability of SARS-CoV-2 as compared with SARSCoV-1. N Engl J Med 2020;382(16):1564-1567

6 Chen Y, Chen L, Deng Q, et al. The presence of SARS-CoV-2 RNA in the feces of COVID-19 patients. J Med Virol 2020;92(7): 833-840 doi:10.1002/jmv.25825

7 Asadi S, Bouvier N, Wexler AS, Ristenpart WD. The coronavirus pandemic and aerosols: Does COVID-19 transmit via expiratory particles?. Aerosol Sci Technol 2020;0(0):1-4 doi:10.1080/ 02786826.2020 .1749229

8 Wang J, Du G. COVID-19 may transmit through aerosol. Ir J Med Sci 2020(e-pub ahead of print). Doi: 10.1007/ s11845-020-02218-2

9 Chen L, Zhao J, Peng J, et al. Detection of SARS-CoV-2 in saliva and characterization of oral symptoms in COVID-19 patients. Cell Prolif 2020;53(12):e12923 doi:10.1111/cpr.12923

10 Meng L, Hua F, Bian Z. Coronavirus disease 2019 (COVID-19): emerging and future challenges for dental and oral medicine. J Dent Res 2020;99(5):481-487

11 Izzetti R, Nisi M, Gabriele M, Graziani F. COVID-19 transmission in dental practice: brief review of preventive measures in Italy. J Dent Res 2020;99(9):1030-1038

12 Li JB, Yang A, Dou K, Wang LX, Zhang MC, Lin XQ. Chinese public's knowledge, perceived severity, and perceived controllability of COVID-19 and their associations with emotional and behavioural reactions, social participation, and precautionary behaviour: a national survey. BMC Public Health 2020;20(1): 1589 doi:10.1186/s12889-020-09695-1

13 Alharbi A, Alharbi S, Alqaidi S. Guidelines for dental care provision during the COVID-19 pandemic. Saudi Dent J 2020;32(4):181-186

14 COVID 19 Dashboard: Saudi Arabia. Available at: https:// covid19.moh.gov.sa/. Accessed June 3, 2020

15 Bandura A. Self-efficacy: toward a unifying theory of behavioral change. Psychol Rev 1977;84(2):191-215

16 Harrison JA, Mullen PD, Green LW. A meta-analysis of studies of the Health Belief Model with adults. Health Educ Res 1992;7(1):107-116

17 Taylor D, Bury M, Campling N, et al. A Review of the use of the Health Belief Model (HBM), the Theory of Reasoned Action (TRA), the Theory of Planned Behaviour (TPB) and the TransTheoretical Model (TTM) to Study and Predict Health Related Behaviour Change. London, UK: National Institute for Health and Clinical Excellence; 2006

18 Ahmed N, Shakoor M, Vohra F, Abduljabbar T, Mariam Q Rehman MA. Knowledge, awareness and practice of health care professionals amid SARS-CoV-2, corona virus disease outbreak. Pak J Med Sci 2020;36(COVID19-S4):S49-S56

19 Hochbaum G, Health behavior. Belmont, CA: Wadsworth Publishing; 1970 
20 Lee YL, Chu D, Chou SY, Hu HY, Huang SJ, Yen YF. Dental care and infection-control procedures during the COVID-19 pandemic: The experience in Taipei City Hospital, Taiwan. J Dent Sci 2020;15(3):369-372 doi:10.1016/j.jds.2020.05.011

21 Zheng L, Wang X, Zhou C, et al. Analysis of the infection status of healthcare workers in wuhan during the COVID-19 outbreak: A cross-sectional study. Clin Infect Dis 2020;71(16):21092113 doi:10.1093/cid/ciaa588

22 Pan Y, Liu H, Chu C, Li X, Liu S, Lu S. Transmission routes of SARS-CoV-2 and protective measures in dental clinics during the COVID-19 pandemic. Am J Dent 2020;33(3):129-134

23 Ahmed MA, Jouhar R, Ahmed N, et al. Fear and practice modifications among dentists to combat novel Coronavirus disease (COVID-19) outbreak. Int J Environ Res Public Health 2020;17(8):2821

24 Brewer NT, Weinstein ND, Cuite CL, Herrington JE. Risk perceptions and their relation to risk behavior. Ann Behav Med 2004;27(2):125-130

25 Funkhouser E, Vellala K, Baltuck C, et al; National Dental PBRN Collaborative Group. Survey methods to optimize response rate in the national dental practice-based research network. Eval Health Prof 2017;40(3):332-358

26 Mafla AC, Divaris K, Herrera-López HM, Heft MW. Self-efficacy and academic performance in Colombian dental students. J Dent Educ 2019;83(6):697-705

27 Chay PL, Nair R, Tong HJ. Pediatricians' self-efficacy affects frequency of giving oral health advice, conducting oral examination, and prescribing referrals. J Dent Child (Chic) 2019;86(3):131-138

28 Melbye ML, Armfield JM. The dentist's role in promoting community water fluoridation: a call to action for dentists and educators. J Am Dent Assoc 2013;144(1):65-75

29 Markowski AM, Greenwood KC, Parker JL, Corkery MB, Dolce MC. A novel interprofessional faculty approach for integrating oral health promotion competencies into a physical therapist curriculum. J Allied Health 2018;47(1):19-24

30 Ellepola AN, Joseph BK, Sundaram DB, Sharma PN. Knowledge and attitudes towards HIV/AIDS amongst Kuwait University dental students. Eur J Dent Educ 2011;15(3):165-171

31 Hedayati H, Marjadi B, Askarian M. Barriers to standard precautions adherence in a dental school in Iran: a qualitative study. Am J Infect Control 2014;42(7):750-754

32 Motamed N, BabaMahmoodi F, Khalilian A, Peykanheirati M, Nozari M. Knowledge and practices of health care workers and medical students towards universal precautions in hospitals in Mazandaran Province. East Mediterr Health J 2006;12(5):653-661

33 Kabbash IA, El-Sayed NM, Al-Nawawy AN, Abou Salem Mel-S, El-Deek B, Hassan NM. Risk perception and precautions taken by health care workers for HIV infection in haemodialysis units in Egypt. East Mediterr Health J 2007;13(2):392-407

34 Azodo CC, Ehigiator O, Oboro HO, et al. Nigerian dental students' willingness to treat HIV-positive patients. J Dent Educ 2010;74(4):446-452

35 Ghorbani B, Shahnazi H, Hassanzadeh A. Improving student's self-efficacy and perceived susceptibility toward oral and dental health: a randomized controlled trial. Oman Med J 2018;33(5):423-428

36 Munro S, Lewin S, Swart T, Volmink J. A review of health behaviour theories: how useful are these for developing interventions to promote long-term medication adherence for TB and HIV/AIDS? BMC Public Health 2007;7(1):104

37 Glanz K, Bishop DB. The role of behavioral science theory in development and implementation of public health interventions. Annu Rev Public Health 2010;31:399-418 